\title{
Professional Competencies in the Field of Educational Psychology Seen From the Perspective of the Students
}

\author{
Verónica Marín-Díaz ${ }^{1, *}$, Ignacio González-López ${ }^{2} \&$ Jorge Figueroa Flores ${ }^{2}$ \\ ${ }^{1}$ Department of Education, Faculty of Education, Universidad de Córdoba, Córdoba, Spain \\ ${ }^{2}$ School of Social and Human Sciences, Universidad del Este, Spain \\ *Corresponding author: Department of Education, Faculty of Education, Universidad de Córdoba, Córdoba, Spain. \\ E-mail:vmarin@uco.es
}

Received: August 29, 2014

Accepted: October 20, $2014 \quad$ Online Published: October 31, 2014

doi:10.5430/wje.v4n6p1

URL: http://dx.doi.org/10.5430/wje.v4n6p1

\begin{abstract}
Determining the professional competencies of a degree is an arduous task that sometimes does not respond to the reality of what society expects for such studies. This article attempts to determine what competencies students in the field of Educational Psychology, which were determined by them. This study was conducted in three different institutions: Universidad de Córdoba, Universidad de Granada, and Universidad de Sevilla. It is based on an awarded innovation project granted by the Office of the Vice Chancellor of Quality and Planning during the $8^{\text {th }}$ call for proposals of one academic year.
\end{abstract}

Keywords: competencies; higher education; European convergence; educational psychology

\section{Introduction}

The current situation faced by universities is in part, based substantially in the ideas that were developed back in the eleventh century, however, issues such as custody of knowledge remain. Some authors (Subirats, 2001) show how the evolution of the universities has been dramatic, marked by the frenetic growth of the societies in which they were and are immersed; however, something is rotten in the paradise of knowledge.

The reality of the offering during the middle of last century by higher education institutions departs from the desire previously stated. During that time the universities were offering a product that didn't covered the demands of society. This was characterized by its demanding technological vision. All these changed when in 1998 the trend of European Higher Education Area (EHEA) appeared.

The university at the moment, the so-called European convergence demand is nothing but a more autonomous, able to produce and transmit valid knowledge for any university center belonging to European Community. At the same time is imperative to know how to develop processes for training, teaching and research within a framework of continuous exchange, in addition to base student learning in skills and competencies to be developed by the learner through his/her professional career (UNESCO, 1998).

The Bologna Declaration (1999) led to the definition of what is and what should be higher education and research today (Ruiz, 2004). It allowed the incorporation of the professionalization of the studies to the formative process, both teachers and students. The new education system creates new parameters that determine what to teach, how to teach, and why to teach, concerning the instructor. Meanwhile, the learners acquired a new dimension. The students are the center of this "new world of knowledge", questioning what to learn, how to learn and why to learn. Since the process began an active participation of the students was encourage. The students became the center of interest and the backbone for the teaching and learning process. According to the Bergen Communique (2005), this participation has been, until now, limited. Changes in the professional profiles should be led by students and not be marked by politicians or other members of society.

Rue (2004:185) mentions that it is needed to implement top-level professional formations that since its implementation work with complex situations and design possible solutions. However, determining the skills that 
college students should possess should not only come from the voice of teachers and experts in higher education, in this process the student's participation is necessary because it is whom he or she will implement at thetime they join the professional ranks.

The new education system should aim to foster a better student/teacher relationship, reflecting the acquired and taught skills (transmitted) and their relation with the following areas of work: What to do? - Functions - Where to do it? - Context - and How to do it? Training.

\section{The Educational Psychologist and the Professional Competencies}

The European Union emphasizes on learning and training throughout life (professional) for all college students. In the case the educational psychologist, it functions will be determined by the skills acquired throughout college and student life. Determining the professional skills of the educational psychologist helps train experts in a particular field, which in this case is no other than human counseling, mentoring and advising.

For Ramos (2005: 51) the development of professional skills of university students generally passes to give greater importance to observations and educational field practice settings that shows a close relationship between learning and doing.

This pursuit of knowledge and homogenization is perceived by some authors like Barkholt (2005) as positive, since it involves resizing learning, teaching methods, and the teaching and development of skills or competencies among other elements necessary to become a good educational psychologist.

Sharing the thoughts of González (2003) that the idea that improving the quality of the university involves, among other things, the improvement of the human capital focusing mainly in the students, it is necessary for those enrolled in these studies to be involved in the development of the competencies both at the beginning and once completed. This is in part to the new system of college education that not only raises the reconversion for the entire professional profiles but as essential members of the academic community (Graz Declaration, 2003: 1).

In 2003, the Ministry of Education of Spain defended the creation of those practices so that students could participate in all areas of higher education conditions; however Sánchez and Zubillaga (2005) showed underdeveloped actions in regards to them. In response, the London Communique (2007) continued it emphasis on the student figure considering that educational psychology students have knowledge in regards to the professionalization of their work during their learning process. This is a field and line of work for further development.

\section{Method}

It was intended during this research to achieve two basic goals:

- Determine the value that students of the Bachelor of Educational Psychology gives to the new competencies system

- Determine the functions of the educational psychologist through the competencies set by the undergraduate students.

The variable control was considered when designing this research and the design selected followed a descriptive model. It is intended to obtain reliable and valid information in a systematic format meaningful and reliable for educators. A field study was conducted in the classroom setting using its natural context.

Based on the level of abstraction, it corresponds to an applied research, which is focused on solving the practical problem involving the right skills and competencies necessary by future educational psychologists. This subject, interest instructors teaching this degree because of the significant outcomes that can be drawn to help in the development of the teaching without losing the student perspective.

This study implemented a quantitative research technique and uses a questionnaire as the data-gathering instrument. The questionnaire is capable of responding to the research objectives proposed. Through the questionnaire, data was obtained through questions posed to the different members of the population and collected information relating to the matter under research. The use of the questionnaire in the research permitted to reach the entire population that makes up the specialties studied.

The instrument consisted of 38 items grouped into four areas/parts of content. In the beginning the purpose of the questionnaire and basic instructions for the completion of the form is mentioned. Then each of the items is presented and finally it concludes with an appreciation message. A description of it is presented below: 
- Part I: Demographics. All the student variables are gathered including: gender, age, previous studies, current course and province where they are taking the Bachelor in Educational Psychology.

- Part II: Cognitive competencies (to know). Using a Likert scale the cognitive competencies to be assimilated by the future educational psychologist are structured.

- Part III: Process competencies (to do). Using the same scale is pretended to gather the procedures and skills which future Educational Psychologists will follow as counselors.

- Part IV: Behavioral competencies (to be). The last items refer to the attitudes that educational psychologists have to take in order to perform the job.

By looking closely at the number of items, there is a significantly higher number than the number of competencies established for an Educational Psychologist in Andalusia; the reason is simple, the accumulation in one competency of several skills c could give rise to confusion by the students surveyed, so it was decided to unfold such competencies for several items.

To conclude this section, the instrument has the sufficient reliability to be applied. This is based after a Cronbach's alpha test or internal consistency test was administered and showed 0.98 of reliability.

One of the key stages in the project, after the data collection and encoding, was the analysis of information. Given the characteristics of the study, essentially quantitative in nature meaning that treatment tends to quantify phenomena, in order to find relations and causal explanations for generalization, justifying and contrasting hypotheses. For this reason several steps were followed. First, a descriptive study of the different variables was carry out in order to discover irregularities or existing features in this data set, as well as its internal organization. Second, and following the objectives a Student $t$ test was conducted and used representative samples and subsequent generalization, or inferential comparative analysis of these data.

The participant sample in this project has been formed by a total of 108 students from three universities and four Andalusian districts as indicated by Table 1 .

Table 1. University Distribution

\begin{tabular}{lll}
\hline University & $\mathrm{f}$ & $\%$ \\
\hline Córdoba & 36 & 33.3 \\
Granada & 28 & 25.9 \\
Granada (Ceuta) & 11 & 10.2 \\
Sevilla & 33 & 30.6 \\
Total & 108 & 100 \\
\hline
\end{tabular}

Students were equally distributed by gender. $48.1 \%$ are men and $51.9 \%$ women. They were relatively young (see Table 2), considering that that they were students from the first and second year course of the second cycle.

Table 2. Age Distribution

\begin{tabular}{lll}
\hline AGE & $\mathrm{f}$ & $\%$ \\
\hline 21-22 years & 48 & 44.4 \\
23-24 years & 28 & 25.9 \\
25-26 years & 11 & 10.2 \\
26 years + & 21 & 19.4 \\
Total & 108 & 100 \\
\hline
\end{tabular}

These students have completed six degrees of the first cycle, belonging to the area of science education. According to the data listed in Table 3, the vast majority has completed teacher education degrees, mainly degrees in Early Childhood Education, Music Education and Foreign Languages. 
Table 3. Previous Degree

\begin{tabular}{lll}
\hline Degree & F & $\%$ \\
\hline Foreign Languages & 17 & 18 \\
Physical Education & 6 & 7 \\
Early Childhood Education & 32 & 34 \\
Musical education & 22 & 24 \\
Primary Education & 8 & 9 \\
Special Education & 7 & 8 \\
Total & 92 & 100 \\
\hline
\end{tabular}

\section{Results}

The first approach toward the assessment of the competencies is offered by the same descriptive study, according to the data of Table 4, all of them seem to have an estimated value above the median $(\mathrm{Mdn}=3)$.

Table 4. Competencies Value

\begin{tabular}{lcc}
\hline Competencies & Median & S \\
\hline 14. - Teamwork & 4,42 &, 810 \\
15. - Interpersonal skills & 4,38 &, 809 \\
5. - Native language oral communication & 4,35 &, 660 \\
18. - Diversity awareness & 4,31 &, 729 \\
19. - Multicultural awareness & 4,31 &, 805 \\
20. - Ethical commitment & 4,31 &, 934 \\
34. - Concern for quality & 4,26 &, 911 \\
2. - Planning and organizing skills & 4,24 &, 722 \\
6. - Native language written communication & 4,24 &, 772 \\
30. - Planning skills & 4,24 &, 853 \\
36. - Learning skills & 4,22 &, 789 \\
25. - Capacity to generate new ideas (creativity) & 4,21 &, 832 \\
21. - Capacity to apply theory to practice & 4,20 &, 925 \\
29. - Ability to work individually & 4,19 &, 742 \\
13. - Self-critical skills & 4,18 &, 778 \\
24. - Capacity to adapt into new situations & 4,18 &, 734 \\
11. - Decision making & 4,17 &, 906 \\
12. - Critical skills & 4,17 &, 951 \\
37. - Ability to work with an interdisciplinary team & 4,15 &, 905 \\
32. - Initiative skills & 4,14 &, 755 \\
10. - Conflict resolution & 4,09 &, 912 \\
33. - Entrepreneurship spirit & 4,08 &, 877 \\
3. - Basic and general knowledge & 4,06 &, 818 \\
4. - Strength within the basic knowledge of the profession & 4,02 &, 985 \\
16. - Ability to communicate with experts from other fields & 4,02 & 1,076 \\
23. - Research skills & 4,00 &, 820 \\
35. - Concern for success & 3,95 &, 901 \\
8. - Ability to retrieve information from other sources & 3,94 &, 694 \\
27. - Capacity to understand cultures from other countries & 3,94 & 1,075 \\
22. - Capacity to engage into environmental quality & 3,93 &, 954 \\
28. - Capacity to understand traditions from other countries & 3,93 & 1,141 \\
31. - Leadership skills & 3,91 &, 826 \\
9. - Ability to analyze information from other sources & 3,90 &, 735 \\
1. - Capacity of analysis and synthesis & 3,82 &, 807 \\
7. - Basic abilities on information technology & 3,79 &, 967 \\
26. - Leadership capacity & 3,67 &, 979 \\
17. - Ability to work under an international context & 3,55 & 1,062 \\
38. - Knowledge of a second language & 3,51 & 1,172 \\
\hline & & \\
\hline
\end{tabular}


The values assigned to the competencies, show great recognition to teamwork and to individual work. It highlights particularly important the ability to learn, as well as to generate new ideas. Secondly, the significance of skills in interpersonal relationships is remarkable. Third, the importance that students offer to both oral and written communication in the native language is seen. Fourth involves diversity awareness, multiculturalism, and ethical commitment. Finally, to emphasize the concern for quality, in addition to organizing and planning capabilities, applying theory to practice, adapting to new situations, decision-making, critical and self-critical skills.

The least valued competence is related to learning a second language, so it is not surprising that among the latter are all related to development work in international contexts, understanding customs of other countries and their culture. Among the least valued is also found the capacity for analysis and synthesis, and skills to retrieve and analyze information from different sources. Other skills noted for its lack of recognition are skills related to information technology; leadership and management, as well as concerns about the success and commitment to environmental quality

No statistically significant differences were noted in the valuation of the items raised in the instrument, taking a course for which students belong, after applying a $t$ test for independent samples $(\mathrm{ns}=0.05$ ). However, after conducting an analysis of variance or ANOVA test, using as criteria the students previous studies the following information was noted:

Table 5. F Value to the Function of Previous Degree

\begin{tabular}{lccl}
\hline Competencies & F & P & \multicolumn{1}{c}{ Previous Degree } \\
\hline 4. - Strength within the basic knowledge of the profession & 2,333 &, 038 & Early Child Edu./Foreign Lang. \\
11.- Decision making & 4,513 &, 000 & Early Child Edu./Phys. Edu. \\
14.- Teamwork & 3,427 &, 004 & Early Child Edu. \\
15.- Interpersonal skills & 4,495 &, 000 & Primary Edu. \\
16.- Ability to communicate with experts from other fields & 2,820 &, 014 & Early Child Edu. \\
17.- Ability to work under an international context & 3,260 &, 006 & Foreign Lang. \\
23.- Research skills & 2,925 &, 012 & Foreign Lang. \\
27.- Capacity to understand cultures from other countries & 8,231 &, 000 & Foreign Lang. \\
28.- Capacity to understand traditions from other countries & 5,562 &, 000 & Foreign Lang. \\
29.- Ability to work individually & 2,915 &, 012 & Foreign Lang. \\
31.- Leadership skills & 2,562 &, 024 & Foreign Lang./Music Edu. \\
36.- Learning skills & 3,507 &, 003 & Foreign Lang. \\
38.- Knowledge of a second language & 5,381 &, 000 & Foreign Lang.
\end{tabular}

As the results show, there are statistically significant differences between the values provided by the students from the different degrees toward the competencies. For example, students with the degree in Education and Physical Education the meaning to competence 11 (decision making), 15 (interpersonal skills) for the students with a degree in Primary Education, and 27, 28 and 38, related to cultural awareness, customs and other languages to those from Foreign Languages.

Meanwhile, after conducting analysis of variance using as criteria the university district in which the students are, the following data was gathered. 
Table 6. F Value in Function of University District

\begin{tabular}{llll}
\hline Competencies & $\mathrm{F}$ & $\mathrm{P}$ & District \\
\hline 3.- Basic and general knowledge & 2,948 &, 036 & Granada \\
7.- Basic abilities on information technology & 2,836 &, 042 Granada \\
15.- Interpersonal skills & 2,835 &, 042 Granada \\
16.- Ability to communicate with experts from other fields & 5,144 &, 002 Granada \\
18.- Diversity awareness & 4,918 &, 003 Granada \\
19.- Multicultural awareness & 7,360 &, 000 Granada \\
20.- Ethical commitment & 3,415 &, 020 Granada \\
21.- Capacity to apply theory to practice & 4,242 &, 007 Granada \\
22.- Capacity to engage into environmental quality & 6,833 &, 000 Granada \\
23.- Research skills & 3,879 &, 011 Ceuta \\
27. - Capacity to understand cultures from other countries & 6,256 &, 001 Granada \\
28. - Capacity to understand traditions from other countries & 6,667 &, 000 Granada \\
31. - Leadership skills & 3,012 &, 033 Granada \\
34. - Concern for quality & 6,396 &, 001 Granada \\
35. - Concern for success & 3,473 &, 019 Ceuta \\
36. - Learning skills & 4,321 &, 006 Ceuta \\
37. - Ability to work with an international team & 3,992 &, 010 Granada \\
\hline
\end{tabular}

Mainly is in the Granada district that it differs significantly with the different competencies, followed by Ceuta. By emphasizing especially in competencies number 19, 22 and 28, two of them related to cultural diversity and the other to quality engagement. In the Ceuta district competencies 23,35 and 36 referring to the ability to research, learn and concern for the success are emphasized.

In order to perform a differential approximation of the skills valued here, the technique of factor analysis was applied, from which explains $79.43 \%$ of the variability of the criterion. A total of seven components were obtained, as shown in Table 7.

Table 7. Obtained Factors

\begin{tabular}{|c|c|c|c|c|c|c|c|}
\hline \multirow[b]{2}{*}{ Competencies } & \multicolumn{7}{|c|}{ Factors } \\
\hline & 1 & 2 & 3 & 4 & 5 & 6 & 7 \\
\hline 1. - Capacity of analysis and synthesis & & & & ,735 & & & \\
\hline 2. - Planning and organizing skills & & & & ,701 & & & \\
\hline 3. - Basic and general knowledge & & & ,459 & ,606 & & & \\
\hline 4. - Strength within the basic knowledge of the profession &, 525 & & & ,495 & & & \\
\hline 5.- Native language oral communication & & & & & & & ,769 \\
\hline 6.- Native language written communication & & & & & & &, 842 \\
\hline 7.- Basic abilities on information technology & & & ,668 & & & & \\
\hline 8.- Ability to retrieve information from other sources & & & & &, 716 & & \\
\hline 9.- Ability to analyze information from other sources & & & & &, 715 & & \\
\hline 10.- Conflict resolution & & & & &, 773 & & \\
\hline 11.- Decision making & & &, 570 & & ,495 & & \\
\hline 12.- Critical skills & & & & & ,486 &, 524 & \\
\hline
\end{tabular}




\begin{tabular}{|c|c|c|c|c|c|c|c|}
\hline \multicolumn{2}{|l|}{ 13.- Self-critical skills } & \multicolumn{3}{|l|}{476} & \multicolumn{3}{|c|}{,458 } \\
\hline 14.- Teamwork & & & & & & & \\
\hline 15.- Interpersonal skills & & & ,732 & & & & \\
\hline 16.- Ability to communicate with experts from other fields & ,476 & & ,635 & & & & \\
\hline 17.- Ability to work under an international context & & & & & & ,615 & \\
\hline 18.- Diversity awareness &, 842 & & & & & & \\
\hline 19.- Multicultural awareness &, 827 & & & & & & \\
\hline 20.- Ethical commitment & ,613 & 440 & & & & & \\
\hline 21.- Capacity to apply theory to practice & ,718 & & & & & & \\
\hline 22.- Capacity to engage into environmental quality & ,769 & & & & & & \\
\hline 23.- Research skills & & & & ,606 & & & \\
\hline 24.- Capacity to adapt into new situations & & 655 & & ,474 & & & \\
\hline 25.- Capacity to generate new ideas (creativity) & & ,688 & & & & & \\
\hline 26.- Leadership capacity & & ,809 & & & & & \\
\hline 27.- Capacity to understand cultures from other countries & ,715 & & & & & & \\
\hline 28.- Capacity to understand traditions from other countries & ,727 & & & & & & \\
\hline 29.- Ability to work individually & & 610 & & & & & \\
\hline 30.- Planning skills & &, 720 & & & & & \\
\hline 31.- Leadership skills & & 627 & & & & & \\
\hline 32.- Initiative skills & & ,658 & & & & & \\
\hline 33.- Entrepreneurship spirit & ,471 & ,680 & & & & & \\
\hline 34.- Concern for quality & ,642 & & & & & & \\
\hline 35.- Concern for success & & ,492 &, 563 & & & & \\
\hline 36.- Learning skills & ,415 & ,646 & & & & & \\
\hline 37.- Ability to work with an interdisciplinary team & &, 570 & & & & & \\
\hline 38.- Knowledge of a second language & & & ,445 & & & 665 & \\
\hline Variance explained & 17,9 & 17,0 & 9,9 & 9,3 & 8,7 & 6,6 & 6,1 \\
\hline
\end{tabular}

The obtained factors, which define the range of competence characters, which shape the professional profile of the educational psychologist, are:

1. Diversity awareness

2. Leadership and planning

3. Social skills

4. Information analysis

5. Organizing information

6. International relations

7. Interpersonal communication

\section{Discussion and Conclusion}

This current research experience is useful for the instructors who perform their teaching in this degree and also for those who work in the conversion of these into a graduate degree.

This research confirmed how competencies are linked to the most important social development work to practice educational psychology as well as the recognition and understanding of attention to diversity; as job skills include all 
competencies related to group work. The skills less valued are those that relate to the exercise of the profession outside their usual environment or atmosphere basically abroad, implying knowledge of a second language.

The 38 variables that make up the questionnaire have been reduced to seven blocks comprehensively summarizing the competencies that determine the students' opinion on the educational psychologist functions. The seven blocks obtained based on the competencies were: diversity awareness, leadership and planning, social skills, analysis of information, organization of information, international relations, and interpersonal communication. They move away from what Roca established in 2001 as professional guidance and counseling functions.

In contrast to the study conducted in Norway in 2003 by researcher Annika Persson where she highlights the low participation of college students in the Bologna Process and Convergence, the students polled expressed interest in participating, which opens a scenario for future work proposals with them.

It's important to mention, as found in the four campuses, the low enrollment of Educational Psychology tstudents. In addition to a constant retention problem during the second year, thar has been seen constantly in three institutions. However, interest by students in completing the questionnaire was high and in the obtained results just like the Bethancourt and Cabera (2012) study which determined that professional profile of the Educational Psychologist is vital at the moment facing employability.

\section{References}

Barkholt, K. (2005). The Bolognia process and integration theory: convergence and autonomy. Higher Education in Europe, 30(1), 23-29. http://dx.doi.org/10.1080/03797720500087980

Bethancourt, J. T., \& Cabrera, L. (2012). Inserción laboral y competencias profesionales del psicopedagogo. Electronic Journal of Research in Educational Psychology, 10(1), 475-504.

Comunicado de Bergen (2005). The European Higher Education Area-Achieving The Goals. Retrieved from www.mec.es/universidades/eees

Comunicado de Londres (2007). Towards the European Higher Education Area: Responding to challenges in a globalised world. Retrieved from

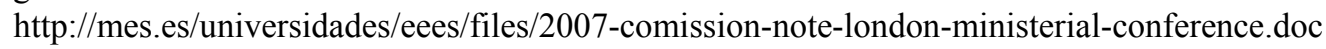

Declaración de Bolonia (1999). The European Higher Education Area. Bologna Declaration. Joint declaration of the European Ministers of Education. Bolonia, 19 de junio de 1999 . Retrieved from http://www.univ.mecd.es/univ/html/informes/bolonia/Declaracion_Bolonia.pdf

Declaración de Graz (2003). Después de Bolonia. El papel de las Universidades. Retrieved from www.mec.es/universidades/eees/files/Declaracion_Graz.pdf

González, I. (2003). Determinación de los elementos que condiciona la calidad de la Universidad: aplicación práctica de un análisis factorial. Revista Electrónica de Investigación y Evaluación Educativa, 9(1). Retrieved from http://www.us.es/RELIEVE/v9n1/RELIEVEv9n1.htm

MEC (2003). La integración del sistema universitario español en el espacio europeo de enseñanza superior. Documento Marco. Retrieved from http://www.mec.es/universidades/ees/files/Documento_Marco.pdf

Persson, A. (2003). Student participation in the governance of higher education in Europe. Retrieved from http://www.mec.es/universidades/eees/files/Oslo_estudiantes.pdf

Ramos, S. (2005). El desarrollo de las competencias didácticas: un reto en la formación de los futuros docentes de primaria. Educar, 35, 49-60.

Ruiz, M. (2004). El espacio europeo de educación superior y las titulaciones de Educación. Revista Interuniversitaria de Formación del Profesorado, 18(3), 61-79.

Sánchez, P., \& Zubillaga, A. (2005). Las Universidades españolas ante el proceso de convergencia europea: análisis de los medios institucionales y acciones de aplicación y coordinación. Revista de Educación, 337, 169-187.

Subirats, J. (2001). Universidad en España: ¿época de cambios o cambio de época? Educar, 28, 11-39.

UNESCO (1998). Declaración mundial sobre la educación superior en el siglo XXI: Visión y acción. Retrieved from http://www.unesco.org//education/educprog/uche/declaration_spa.htm 